\author{
Multidisciplinary Journal \\ Journal homepage: https://jurnal.unej.ac.id/index.php/multijournal
}

\title{
Pengaruh Usia Dan Pendidikan Terhadap Implementasi nisiasi Menyusu Dini (IMD) Pada Pasien Post Sectio Caesarea
}

\author{
The Effect of Age and Education on the Implementation of Early Initiation Breastfeeding (EIBF) \\ in Post Sectio Caesarea Patients
}

\author{
Meylina Parela Ningsih ${ }^{1}$, FX. Ady Soesetijo ${ }^{2}$, Dewi Rokhmah ${ }^{3}$ \\ ${ }^{1}$ Pascasarjana Ilmu Kesehatan Masyarakat Universitas Jember \\ ${ }^{2}$ Program Studi Ilmu Kedokteran Gigi Univeristas Jember \\ ${ }^{3}$ Program Studi Ilmu Kesehatan Masyarakat Universitas Jember \\ Email: meylina05@gmail.com \\ Artikel Diterima: DD MM 2020 . Proses Submit: , Revisi: 2020.
}

\begin{abstract}
Inisiasi menyusu dini (IMD) pada pasien post sectio caesarea merupakan proses menyusu bayi kepada ibunya segera setelah lahir dengan meletakkan bayi di dada atau perut ibu agar terjadi kontak kulit ibu dan bayi (skin to skin contact) dan membiarkan bayi mencari sendiri puting susu ibunya lalu menyusu sampai puas. Manfaat dari IMD ini sangat besar bagi ibu dan bayi diantaranya mempercepat pengeluaran kolostrum sebagai antibodi bayi sehingga mencegah terjadinya infeksi, mencegah terjadinya hipotermia dan hipoglikemia serta mencegah anemia akibat perdarahan setelah melahirka. Dengan demikian IMD ini menjadi penting untuk dilaksanakan baik bagi ibu dengan persalinan normal maupun dengan tindakan sectio caesarea. Penelitian ini bertujuan untuk mengetahui pengaruh usia dan pendidikan ibu terhadap implementasi inisiasi menyusu dini (IMD) pada pasien post sectio caesarea. Jenis penelitian ini adalah observasional analitik dengan desain cross sectional. Lokasi penelitian di Rumah Sakit Bina Sehat Jember pada bulan April 2021. Data yang diperoleh dari data primer 99 responden dengan mengisi kuesioner dan melakukan observasi langsung. Analisis data yang digunakan adalah analisis bivariat menggunakan alat pengolah data statistik SPSS. Hasil pengujian instrumen menunjukkan bahwa semua variabel valid dan reliabel sebagai alat pengumpul data. Hasil analisis data menunjukkan bahwa: 1) Usia tidak berpengaruh signifikan terhadap implementasi IMD pada pasien post sectio caesarea $(\mathrm{p}=0,769)$ karena indikasi persalinan dengan sectio caesarea tidak dilakukan pada pasien dengan usia resiko tinggi, tetapi juga pada usia produktif. 2) Pendidikan tidak berpengaruh signifikan terhadap implementasi IMD pada pasien post sectio caesarea $(\mathrm{p}=0,284)$ karena pengetahuan tentang pentingnya inisiasi menyusu dini dan bagaimana cara melakukannya tidak didapatkan selama pendidikan formal melainkan dari pendidikan non formal dan media edukasi lainnya, sehingga diperlukan media edukasi yang lain agar dapat mendukung pelaksanaan IMD terutama pada pasien post sectio cesarea.
\end{abstract}

Kata Kunci: Inisiasi Menyusu Dini, Pendidikan, Sectio Caesarea,Usia

ABSTRACT. Early initiation of breastfeeding (EIBF) in post sectio caesarea patients is the process of breastfeeding the baby to his mother immediately after birth by placing the baby on the mother's chest or abdomen so that skin-to-skin contact occurs and letting the baby find the mother's nipple and then breastfeed until satisfied. The benefits of IMD are very large for mothers and babies including accelerating the production of colostrum as a baby antibody so as to prevent infection, prevent hypothermia and hypoglycemia and prevent anemia due to bleeding after delivery. IMD becomes important to be carried out both for mothers with normal labor and with the act of sectio caesarea. This study aims to determine the effect of maternal age and education on the implementation of early initiation of breastfeeding (IMD) in post sectio caesarea patients. This type of research was analytic observational with cross sectional design. Data obtained from primary data 99 respondents by filling out a questionnaire and direct observation. The research site at Bina Sehat Jember Hospital in April 2021. Data obtained from the primary data of 99 respondents by filling out questionnaires and making direct observations. Data analysis used is bivariate analysis using SPSS statistical data processing tool. The results of the instrument test show that all variables were valid and reliable as a data collection tool. The results of data analysis showed that: 1) Age had no significant effect on the implementation of IMD in post sectio caesarea patients $(p=0.769)$ because the indication for delivery by sectio caesarea was 
not carried out in patients with high risk age, but also in productive age. 2) Education had no significant effect on the implementation of IMD in post sectio caesarea patients $(p=0.284)$ Because knowledge about the importance of early breastfeeding initiation and how to do it is not obtained during formal education but from non-formal education and other educational media, so that other educational media are needed in order to support the implementation of IMD, especially in post sectio cesarea patients.

Keywords: Early Initiation Breastfeeding, Education, Sectio Caesarea, Age

\section{Pendahuluan}

Sustainable Development Goals (SDGs) merupakan suatu rencana aksi global yang disepakati oleh para pemimpin dunia, termasuk Indonesia, guna mengakhiri kemiskinan, mengurangi kesenjangan dan melindungi lingkungan dalam periode 2016 sampai dengan 2030. ${ }^{1}$ SDGs memiliki 17 tujuan utama, salah satunya untuk meningkatkan derajat kesehatan masyarakat dengan menurunkan angka kematian ibu dan kematian bayi. ${ }^{2}$ Data Perserikatan Bangsa-Bangsa (PBB) di Indonesia pada tahun 2019 lalu angka kematian bayi adalah 21,12\%. ${ }^{3}$ Angka ini menurun dari catatan pada tahun 2018 ketika angka kematian bayi di Indonesia masih mencapai 21,86\% atau pada tahun 2017 yang mencapai $22,62 \%{ }^{4}$ Hal ini terjadi penurunan angka kematian bayi, namun target SDGs pada tahun 2030 yaitu menurunkan angka kematian neonatal setidaknya hingga 12 per 1000 kelahiran hidup kemungkinan masih belum bisa tercapai. ${ }^{3}$

Meskipun mengalami penurunan angka kematian bayi yang signifikan dalam tiga tahun terakhir, $\mathrm{AKB}$ di Indonesia masih tergolong tinggi dibanding negara Asia Tenggara lainnya. ${ }^{1}$ Tahun 2019, negara Asia Tenggara dengan angka kematian bayi paling rendah adalah Singapura (2,26), disusul Malaysia $(6,65)$, Thailand (7,80), Brunei Darussalam $(9,83)$, dan Vietnam $(16,50) .{ }^{3}$ Kematian bayi di Jawa Timur pada tahun 2019 sebanyak 4059. Jumlah kematian bayi tertinggi yaitu sebanyak 223 jiwa terdapat di Kabupaten Jember, sehingga harus mendapat perhatian khusus dari pemerintah, terutama di wilayah Kabupaten Jember. ${ }^{2}$

Upaya terobosan yang akan dilakukan pemerintah Menurut Arah Kebijakan dan Rencana Aksi Program Kesehatan Masyarakat Tahun 2020-2024, untuk menurunkan Angka Kematian Bayi (AKB) adalah dengan langkah pencegahan yang sederhana. ${ }^{2}$ Contoh pencegahan ini ialah melakukan skin to skin antara ibu dan bayi baru lahir dan menyusui secara eksklusif selama 6 bulan. $^{5}$ Inisiasi Menyusu Dini (IMD) merupakan kontak antara kulit ibu dengan kulit bayi sesegera mungkin dalam waktu satu jam setelah bayi dilahirkan. Bayi baru lahir diletakkan di dada atau perut ibu dengan kulit ibu melekat pada kulit bayi tanpa adanya penghalang apapun. ${ }^{6}$

Data WHO tahun 2017, sebesar 65,5\% angka capaian IMD nasional, dan data Riskesdas 2018, sebesar $63,7 \%$ angka capaian IMD nasional. ${ }^{2}$ Sedangkan lama waktu menyusu kurang dari 1 jam sebesar $81,9 \%$ dan lama waktu lebih dari 1 jam sebesar 18,1\%. ${ }^{7}$ Badan Pusat Statistik (BPS) provinsi Jawa Timur juga menyebutkan di Jawa Timur sendiri lama waktu menyusu kurang dari 1 jam sebesar 84,9\% dan lama menyusu lebih dari 1 jam sebesar 15,10\%. Tahun 2019 di Kabupaten Jember, data IMD sebesar 77\%. ${ }^{7}$ Kementerian Kesehatan mencatat, angka inisiasi menyusui dini (IMD) di Indonesia meningkat dari 51,8\% pada tahun 2016 menjadi 57,8\% pada tahun $2017 .^{2}$ Meskipun sudah meningkat, angka tersebut masih jauh dari target sebesar 90\%. Implementasi kebijakan berdasarkan Peraturan Pemerintah RI Nomor 33 Tahun 2012 yang menyatakan bahwa tenaga kesehatan dan penyelenggara pelayanan kesehatan wajib melakukan inisiasi menyusu dini terhadap bayi baru lahir kepada ibunya paling singkat selama 1 jam. $^{8}$

Inisiasi Menyusu Dini dilakukan dengan cara meletakkan bayi secara tengkurap di dada atau perut ibu sehingga kulit bayi melekat pada kulit ibu. ${ }^{9}$ Bagga, et al. (2018) dalam penelitiannya menjelaskan bahwa penelitian yang dilakukan di ruang ICU rumah sakit India, didapatkan dari 30 bayi prematur mengalami peningkatan berat badan pada hari ke 2 dan 3 sebesar $80 \%$ dari $24 \%$ dan pada hari ketujuh meningkat $73 \%$ dari $46 \%$ setelah diberikan ASI eksklusif. ${ }^{10}$ Keberhasilan ASI ekslusif ini juga dipengaruhi dengan adanya inisiasi menyusu dini. ${ }^{11}$

Penentu utama penghambat inisiasi menyusu dini adalah ibu yang melahirkan melalui operasi sectio caesarea, tingkat pendidikan yang rendah, tidak menerima informasi menyusui, tidak memiliki pengetahuan tentang waktu yang tepat untuk menyusui, serta wilayah tempat tinggal. ${ }^{12}$ Patel (2015) menjelaskan bahwa angka IMD di Pakistan rendah karena melahirkan banyak anak, persalinan dengan sectio caesarea dan kehamilan kembar. ${ }^{13}$ Pendidikan, usia ibu melahirkan dan dukungan keluarga memberikan hasil yang 
signifikan terhadap inisiasi menyusu dini. ${ }^{27}$ Keputusan untuk segera menyusui tidak hanya bergantung pada ibu, tetapi juga peran keluarga, masyarakat, sumber informasi dan pelayanan kesehatan di Afrika-Amerika. ${ }^{25}$

Inisiasi menyusu dini dilakukan pada ibu postpartum, baik postpartum normal maupun post Sectio Caesarea. ${ }^{14}$ Dengan melakukan IMD, tidak hanya bermanfaat bagi bayi baru lahir, tetapi juga pada ibu yang baru melahirkan, yaitu menurunkan resiko perdarahan setelah melahirkan serta meningkatkan bounding attachment antara ibu dan bayi. ${ }^{15}$ Mengingat penyumbang Angka Kematian Ibu terbesar adalah perdarahan setelah melahirkan. ${ }^{2}$ Program pemerintah tentang inisiasi menyusu dini (IMD) terdapat dalam peraturan pemerintah nomor 33 ahun 2012 pada pasal 9 ayat (1) dan (2) dan pasal 10 ayat (1) dan (2). ${ }^{8}$

Tujuan penelitian ini adalah untuk mengetahui pengaruh usia dan tingkat pendidikan terhadap implementasi inisiasi menyusu dini pada pasien post sectio caesarea.

\section{Bahan dan Metode}

Penelitian ini merupakan penelitian kuantitatif observasional dengan jenis penelitian cross sectional. Populasi dalam penelitian ini adalah seluruh ibu yang melahirkan sectio caesarea pada bulan April 2021 dengan jumlah sampel sebanyak 99 responden.

Variabel penelitian terbagi atas variabel independen yaitu usia dan pendidikan serta variabel dependen implementasi IMD. Penelitian ini menggunakan data primer yang berasal dari responden dengan mengisi kuesioner yang dibagikan oleh peneliti serta hasil observasi langsung oleh peneliti.

\section{Waktu dan Tempat}

Waktu untuk melakukan penelitian ini adalah satu bulan, yakni bulan April 2021, mulai dari pengambilan data sampai penyusunan hasil. Tempat penelitian di ruang rawat gabung rumah sakit Bina Sehat. Peneliti memilih tempat tersebut karena data ibu bersalin yang melebihi 100 ibu setiap bulannya, mudah dijangkau peneliti sehingga mendukung peneliti untuk pengambilan data dan sebelumnya belum pernah dilakukan penelitian dengan judul yang serupa.

\section{Bahan dan Alat}

Instrumen yang digunakan dalam penelitian ini adalah kuesioner dan lembar observasi. Kuesioner yang berisi daftar pertanyaan terstruktur yang digunakan untuk mengumpulkan data penelitian dari responden agar data yang diperoleh valid dan realibel. Lembar observasi yang berisi sejumlah pernyataan yang dijadikan acuan peneliti untuk mengamati implementasi inisiasi menyusu dini.

\section{Prosedur Penelitian}

Prosedur penelitian dalam penelitian ini adalah sebagai berikut :

1. Tahap konseptual (merumuskan dan memgidentifikasi masalah, meninjau kepustakaan yang relevan, mendefinisikan kerangka teoritis, merumuskan hipotesis).

2. Fase perancangan dan perencanaan (memilih rancangan penelitian, mengidentifikasi populasi yang diteliti, mengkhususkan metode untuk mengukur variabel penelitian, merancang rencana sampling, mengakhiri dan meninjau rencana penelitian, melaksanakan penelitian dan melakukan revisi).

3. Membuat instrumen dan pengumpulan data penelitian.

4. Fase empirik (pengumpulan data, persiapan data untuk di analisis) mengumpulkan data penelitian yang telah dilaksanakan di lapangan.

5. Fase analitik (menganalisis data dan menghitung hasil data penelitian), mengolah dan mengalisis data hasil penelitian. Data yang telah dikumpulkan dari lapangan diolah dan dianalisis untuk mendapatkan kesimpulan-kesimpulan yang diantaranya kesimpulan dari hasil pengujian hipotesis penelitian.

6. Fase diseminasi (mendesain hasil penelitian). Pada tahap akhir, agar hasil penelitian dapat dibaca, dimengerti, dan diketahui oleh pembaca maka hasil penelitian tersebut disusun dalam bentuk kesimpulan dari hasil penelitian.

Analisis data yang digunakan dalam penelitian ini merupakan analisis bivariat menggunakan uji regresi ordinal yang dianalisis menggunakan SPSS.

\section{Etika Penelitian}

1. Informed consent dengan memberikan lembar persetujuan kepada responden sebelum melakukan penelitian yang kemudian ditandatangani apabila bersedia menjadi responden penelitian.

2. Anonimity dengan tidak menyebutkan nama lengkap pada lembar yang digunakan untuk mengumpulkan data dari responden, cukup menuliskan kode tertentu.

3. Confidentiality dengan menjaga kerahasiaan informasi dari responden sesuai dengan tujuan penelitian yang akan dilaporkan sebagai hasil penelitian. 
4. Tersertifikasi komite etik penelitian kesehatan (KEPK) melalui pengurusan komite etik di Fakultas Kedokteran Gigi Universitas Jember.

\section{Hasil dan Pembahasan}

Hasil penelitian yang diperoleh adalah sebagai berikut :

Tabel 1. Distribusi Frekuensi Usia Dan Pendidikan Responden

\begin{tabular}{|c|c|c|c|c|}
\hline \multirow{2}{*}{ No. } & \multirow{2}{*}{ Karakteristik } & \multirow{2}{*}{ Kategori } & \multicolumn{2}{|c|}{ Total } \\
\hline & & & $\mathrm{n}$ & $\%$ \\
\hline \multirow[t]{7}{*}{1.} & Usia & $<18$ tahun & 1 & $1,01 \%$ \\
\hline & & 18-28 tahun & 31 & 31,31 \\
\hline & & 29-39 tahun & 62 & $\%$ \\
\hline & & $>40$ tahun & 5 & 62,63 \\
\hline & & & & $\%$ \\
\hline & & & & $5,05 \%$ \\
\hline & \multicolumn{2}{|l|}{ Total } & 99 & $100 \%$ \\
\hline \multirow[t]{8}{*}{2.} & Tingkat & Tamat SD & 5 & $5,05 \%$ \\
\hline & Pendidikan & Tamat SMP & 25 & 25,25 \\
\hline & & Tamat SMA & 36 & $\%$ \\
\hline & & Perguruan & 33 & 36,36 \\
\hline & & Tinggi & & $\%$ \\
\hline & & & & 33,33 \\
\hline & & & & $\%$ \\
\hline & Total & & 99 & $100 \%$ \\
\hline
\end{tabular}

Tabel 1 merupakan ditribusi frekuensi responden berdasarkan usia dan pendidikan. Mayoritas responden berusia 29 sampai 39 tahun 62,63\% (62 responden) dan paling sedikit responden yang berusia kurang dari 18 tahun $1,01 \%$ (satu responden). Sebagian besar tingkat pendidikan responden adalah tamat SMA 36,36\% dan paling sedikit pendidikan responden adalah tamat SD $5,05 \%$ (lima responden).

Tabel 2. Hasil Uji Regresi Ordinal

\begin{tabular}{llllll}
\multicolumn{1}{c}{ Variabel } & Estimate & Std. Error & Wald & df & Sig. \\
\hline IMD & -1.321 & 1.192 & 1.228 & 1 & .268 \\
\hline Usia & & & & & \\
$\quad<18$ Tahun & .482 & .000 &. & 1 &. \\
$\quad>40$ Tahun & .390 & 1.331 & .086 & 1 & .769 \\
18-28 Tahun & .793 & 1.253 & .401 & 1 & .527 \\
29-39 Tahun & $0^{\mathrm{a}}$ &. &. & 0 &. \\
\hline Jenjang Pendidikan & & & & & \\
SD & 17.245 & 6012.528 & .000 & 1 & .998 \\
SMP & 1.227 & 1.184 & 1.073 & 1 & .300 \\
SMA & -.780 & .727 & 1.149 & 1 & .284 \\
PT & $0^{\mathrm{a}}$ &. &. & 0 &. \\
\hline
\end{tabular}

Tabel 2 di atas menunjukkan bahwa nilai wald variabel usia dengan kategori 18-28 tahun sebesar 0,401 dengan sig. 0,527 $(>0,05)$. Hal ini berarti bahwa usia tidak berpengaruh signifikan terhadap inisiasi menyusu dini (IMD). Sedangkan nilai wald untuk variabel jenjang pendidikan SMA sebesar 1,149 denga sig. 0,284 (>
0,05). Hal ini menunjukkan jenjang pendidikan tidak berpengaruh signifikan terhadap pelaksanaan IMD.

\section{Pembahasan}

\subsection{Pengaruh Usia Terhadap Implementasi IMD Pada Pasien Post Sectio Caesarea \\ Berdasarkan hasil penelitian yang telah} diperoleh dari 99 responden bahwa sebagian besar usia responden antara 29 hingga 39 tahun. Hal ini karena ibu yang mempunyai resiko rendah terhadap persalinan adalah usia produktif antara 20 - 35 tahun, sedangkan ibu yang mempunyai resiko tinggi adalah usia non produktif yaitu berumur kurang dari 20 tahun dan lebih dari 35 tahun. ${ }^{16}$ Ibu yang melahirkan untuk pertama kali pada usia sekitar 35 tahun ke atas memiliki resiko melahirkan dengan persalinan SC, demikian juga ibu yang melahirkan dengan usia kurang dari 20 tahun. ${ }^{17}$

Pada usia lebih dari 35 tahun organ-organ kandungan sudah menuju menopouse, sehingga dalam pertimbangan medis akan berbahaya bila dilakukan persalinan normal atau spontan maka dokter memutuskan persalinan dengan sectio caesarea. ${ }^{16}$ Bila usia ibu saat melahirkan kurang dari 20 tahun, maka kecenderungan dilakukan persalinan secara SC dapat dipertimbangkan juga, karena organ-organ kandungan saat umur kurang dari 20 tahun belum matang. ${ }^{15}$

Usia terbanyak pada responden antara 29 sampai dengan 39 tahun, hal ini selain karena usia diatas 35 tahun merupakan resiko tinggi melahirkan normal usia 29 tahun merupakan usia produktif sehingga tidak hanya dengan melihat indikasi faktor usia, riwayat persalinan sebelumnya dilakukan operasi sectio caesarea juga menjadi faktor pertimbangan tindakan SC. ${ }^{16}$ Keterkaitan dengan inisiasi menyusu dini bahwa usia antara 29 hingga 39 tahun cenderung telah memiliki kesiapan dalam persalinannya termasuk dalam hal memberikan ASI dan nutrisi pada bayinya. ${ }^{17}$

Dalam penelitian ini didapatkan nilai signifikansi $(p$ value 0,769$)>$ dari alpha 0,05 sehingga $\mathrm{H} 0$ diterima atau tidak terdapat pengaruh signifikan usia ibu terhadap implementasi inisiasi menyusu dini (IMD) pada pasien post sectio caesarea. Hal ini bertolak belakang dengan penelitian yang dilakukan Putri (2020) yang menunjukkan bahwa adanya hubungan antara umur, pendidikan, pengetahuan, dan sikap dengan IMD dan pemberian ASI eksklusif. ${ }^{18}$ Namun sejalan dengan penelitian Amin (2014) yang menyatakan bahwa hasil penelitiannya tidak menemukan adanya pengaruh yang bermakna antara umur ibu dengan keberhasilan menyusui pada dua bulan pertama $(\mathrm{p}=0,572) .{ }^{19}$ 
Penelitian yang dilakukan Raharjo (2014) juga menyatakan bahwa umur yang merupakan faktor ibu tidak berhubungan signifikan dengan praktik IMD ( $p=$ 0,369), yang berhubungan langusng dengan praktik IMD adalah sikap dan pengetahuan ibu. ${ }^{20}$ Penelitian serupa yang dilakukan Nopa (2019) juga mendapatkan hasil bahwa usia tidak memiliki hubungan yang bermakna ( $p$ $=0,133$ ) dengan motivasi ibu hamil trimester tiga dalam melaksanakan IMD. ${ }^{21}$ Sedangkan penelitian Bongga (2019) mendapatkan hasil bahwa sebesar $72 \%$ rata-rata ibu yang berusia usia 20 tahun sampai 30 tahun melaksanakan IMD. ${ }^{22}$

Hasil yang didapatkan dari penelitian ini tidak terdapat pengaruh yang signifikan usia ibu terhadap pelaksanaan IMD. Namun usia ideal perempuan untuk menikah dan melahirkan adalah pada rentang usia 21-35 tahun dengan jarak kelahiran dua sampai lima tahun karena dalam periode kehidupan ini, risiko wanita menghadapi komplikasi medis ketika hamil dan melahirkan tergolong yang paling rendah. Sedangkan pada usia $<20$ tahun dan $>35$ tahun merupakan usia yang berisiko tinggi terhadap kelahiran dan persalinan. ${ }^{23}$ Dengan demikian usia tidak dapat menjadikan alasan utama untuk indikasi persalinan dengan sectio caesarea karena tidak selalu usia resiko tinggi melahirkan dengan sectio caesarea akan tetapi ada indikasi kegawatan lain yang selanjutnya akan melaksakan inisiasi menyusu dini setelah tindakan operasi.

\subsection{Pengaruh Pendidikan Terhadap Implementasi IMD Pada Pasien Post Sectio Caesarea}

Hasil penelitian diperoleh dari 99 responden bahwa sebagian besar $(36,36 \%)$ pendidikan responden adalah tamat SMA. Dalam penelitian ini didapatkan nilai signifikansi ( $p$ value 0,284$)>$ dari alpha 0,05 sehingga H0 diterima atau tidak terdapat pengaruh signifikan pendidikan ibu terhadap implementasi inisiasi menyusu dini (IMD) pada pasien post sectio caesarea.

Hasil yang didapatkan sejalan dengan penelitian yang dilakuakan oleh Raharjo (2014) bahwa tidak terdapat hubungan yang signifikan tingkat pendidikan dengan praktik IMD $(\mathrm{p}=0,216) .{ }^{20}$ Sejalan juga dengan penelitian yang dilakukan Nopa (2019) yang menyatakan bahwa tidak terdapat hubungan yang bermakna tingkat pendidikan $(\mathrm{p}=0,310)$ dengan motivasi ibu hamil trimester III dalam melaksanakan IMD. $^{21}$

Berbeda dengan penelitian yang dilakukan Nisa et al (2017) yang menunjukkan hasil bahwa terdapat hubungan yang signifikan tingkat pendidikan ( $\mathrm{p}=$ $0,030)$ dengan lama waktu inisiasi menyusu dini. ${ }^{24} \mathrm{Hal}$ ini karena tingkat pendidikan berpengaruh dalam memberikan respon terhadap segala sesuatu yang datang dari luar, dimana pada seseorang dengan pendidikan tinggi akan memberikan respon lebih rasional daripada yang berpendidikan menengah atau rendah, selanjutnya menunjukkan kesadaran dan usaha pencapaian atau peningkatan derajat kesehatan yang lebih baik pada yang berpendidikan tinggi daripada yang berpendidikan menengah atau rendah, karena pendidikan dapat mempengaruhi pengetahuan dalam pembentukan sikap mereka tentang tindakan sectio caesarea, pendidikan dapat membentuk keyakinan tertentu sehingga seseorang dapat mempunyai minat, kemampuan, pengalaman, ketrampilan dan tingkat perhatian. ${ }^{24}$

Penelitian Bongga (2019) juga menyebutkan bahwa sebesar $52 \%$ pada tingkat pendidikan menengah ibu mempengaruhi pengetahuan ibu gravida I tentang IMD. ${ }^{22}$ hal ini karena pendidikan akan memudahkan seseorang menerima masukan atau pendapat maupun pemahaman tentang sesuatu seperti IMD. Tingkat pendidikan ibu yang rendah mengakibatkan kurangnya pengetahuan ibu dalam melaksanakan IMD. Sedangkan ibu yang mempunyai tingkat pendidikan yang lebih tinggi, umumnya terbuka dalam menerima perubahan dalam pemeliharaan kesehatannya. ${ }^{22}$

Hasil penelitian yang didapatkan sama halnya dengan penelitian yang dilakukan Putrianti, dkk (2017) bahwa variabel tingkat pendidikan tidak terdapat hubungan dengan pelaksanaan Inisiasi Menyusu Dini (IMD) di Klinik Aminah Amin Samarinda $(p=0,435) .{ }^{25}$ Hal ini karena pendidikan dapat mempengaruhi proses belajar, makin tinggi pendidikan seseorang semakin mudah orang tersebut untuk menerima informasi, dengan pendidikan yang tinggi, wawasan serta usaha dalam menerima informasi juga kan lebih luas, lebih mudah mengerti dan memahami informasi dan perlakuan yang diterimanya dibandingkan dengan yang berpendidikan rendah. ${ }^{25}$ Pendidikan juga merupakan paya persuasi atau pembelajaran kepada masyarakat agar masyarakat ingin melakukan tindakan-tindakan (praktik) untuk memelihara (mengatasi masalah-masalah) dan meningkatkan kesehatannya. ${ }^{26}$

Tingkat pendidikan ibu tidak berpengaruh signifikan terhadap implementasi IMD pada pasien post sectio caesarea disebabkan oleh karena pengetahuan tentang pentingnya inisiasi menyusu dini dan bagaimana cara melakukannya tidak didapatkan selama pendidikan formal. Informasi terkait IMD didapatkan dari tenaga kesehatan dan media informasi lain pada saat kehamilan. 


\section{Kesimpulan}

Sebagian besar usia responden antara 29 sampai 39 tahun, serta pendidikan responden tamat SMA. Usia tidak berpengaruh signifikan terhadap implementasi inisiasi menyusu dini (IMD) karena indikasi persalinan dengan sectio caesarea tidak dilakukan pada pasien dengan usia resiko tinggi, tetapi juga pada usia produktif. Pendidikan juga tidak berpengaruh siknifikan terhadap implementasi inisiasi menyusu dini (IMD) karena pengetahuan tentang pentingnya inisiasi menyusu dini dan bagaimana cara melakukannya tidak didapatkan selama pendidikan formal, melainkan dari pendidikan informal dan media edukasi yang lain dari tenaga kesehatan pada masa kehamilan.

\section{Saran :}

Untuk peneliti selanjutnya diharapkan melakukan penelitian terkait secara lebih lanjut, upaya pelaksanaan inisiasi menyusu dini (IMD) agar tetap dilaksanakan, terutama pada pasien dengan persalinan sectio caesarea.

\section{Ucapan Terimakasih}

Terima kasih kepada seluruh ibu post sectio caesarea yang telah bersedia menjadi responden serta Rumah Sakit Bina Sehat Jember yang telah berkenan memberikan ijin atas pelaksanaan penelitian ini.

\section{Acuan Referensi}

[1] Aminullah, A. A. H., \& Purhadi, P. (2020). Pemodelan untuk Jumlah Kasus Kematian Bayi dan Ibu di Jawa Timur Menggunakan Bivariate Generalized Poisson Regression. Jurnal Sains dan Seni ITS, 8(2), D72-D78. 10.12962/j23373520.v8i2.44693.

[2] Kementerian Kesehatan Republik Indonesia. 2018. Laporan Nasional Riskesdas 2018. Jakarta: Badan Penelitian Dan Pengembangan Kesehatan RI.

[3] UNICEF. 2016. Laporan Tahunan 2015. United Nations Children's Fund.

[4] Adam, A., Bagu, A. A., \& Sari, N. P. (2016). Pemberian inisiasi menyusu dini pada bayi baru lahir. Jurnal Kesehatan Manarang, 2(2), 76-82. https://doi.org/10.33490/jkm.v2i2.19.

[5] Roesli, Utami. 2012. Panduan Inisiasi Menyusu Dini Plus ASI Eksklusif. Jakarta: Pustaka Bunda.

[6] Bagga, N., Nadipineni, R., Mohamed, A., Poddutoor, P., \& Chirla, D. K. (2018). A quality initiative to improve exclusive breast milk feeding in preterm neonates. International Journal of Pediatrics and Adolescent Medicine, 5(4), 131-134. https://doi.org/10.1016/j.ijpam.2018.12.003

[7] Raihana, S., Dibley, M. J., Rahman, M. M., Tahsina, T., Siddique, M. A. B., Rahman, Q. S. \& Huda, T. M. (2019). Early initiation of breastfeeding and severe illness in the early newborn period: An observational study in rural Bangladesh. PLoS medicine, 16(8), e1002904. https://doi.org/10.1371/journal.pmed.1002904
[8] Ahmed, A. E., \& Salih, O. A. (2019). Determinants of the early initiation of breastfeeding in the Kingdom of Saudi Arabia. International breastfeeding journal, 14(1), 13. https://oi.org/10.1186/s13006-019-0207-z

[9] Patel, A., Bucher, S., Pusdekar, Y., Esamai, F., Krebs, N. F., Goudar, S. S., ... \& Hibberd, P. L. (2015). Rates and determinants of early initiation of breastfeeding and exclusive breast feeding at 42 days postnatal in six low and middleincome countries: a prospective cohort study. Reproductive Health, 12(2), 1-11. https://doi.org/10.1186/1742-4755-12-S2S10

[10] Manuaba, I.A.C., Manuaba, I.B.G.F., Manuaba, I.B.G. 2008. Gawat Darurat Obstetri Ginekologi Dan Obstetri Ginekologi Sosial Untuk Profesi Bidan. Jakarta: EGC.

[11] Putri, N. Z. (2016). Hubungan Antara Faktor Ibu Dan Inisiasi Menyusu Dini (Imd) Dengan Pemberian Asi Eksklusif Oleh Ibu Multipara Pada Bayi Usia 6-12 Bulan (Studi Di Wilayah Kerja Puskesmas Pademawu, Kecamatan Pademawu, Kabupaten Pamekasan).

Http://Repository.Unej.Ac.Id/Handle/123456789/75787

[12] Amin, W., Indrawan, I. W. A., \& Sriwahyuni, E. (2014). Pengaruh faktor sosial ibu terhadap keberhasilan menyusui pada dua bulan pertama. Jurnal Kedokteran Brawijaya, 28(2), 146151.

[13] Raharjo, B. B. (2014). Profil ibu dan peran bidan dalam praktik inisiasi menyusu dini dan asi eksklusi. KEMAS: Jurnal Kesehatan $\quad$ Masyarakat, 10(1), 53-63. https://doi.org/10.15294/kemas.v10i1.3070

[14] Nopa, I. (2019). Faktor Yang Berhubungan Dengan Motivasi Ibu Hamil Trimester Tiga Dalam Melaksanakan Inisiasi Menyusu Dini (IMD) di Puskesmas Kecamatan Medan Denai. Saintika Medika: Jurnal Ilmu Kesehatan dan Kedokteran Keluarga, 15(1), 33-40. https://doi.org/10.22219/sm.Vol15.SMUMM1.8483

[15] Bongga, S. (2019). Faktor-Faktor Yang Mempengaruhi Pengetahuan Ibu Gavida I Tentang Inisiasi Menyusu Dini (IMD) Di Puskesmas Sa'dan Kab. Toraja Utara Tahun 2018. MPPKI (Media Publikasi Promosi Kesehatan Indonesia): The Indonesian Journal of Health Promotion, 2(2), 93-98. 10.31934/mppki.v2i2.563

[16] BKKBN. (2017). Peraturan Kepala Badan Kependudukan dan Keluarga Berencana Nasional Nomor 24 tahun 2017 tentang Pelayanan Keluarga Berencana Pasca Persalinan dan Pasca Keguguran. Jakarta: BKKBN.

[17] Nisa, J., Salimo, H., \& Budihastuti, U. R. (2017). Factor of socio demography and obstetric that influence the timeliness of early breastfeeding in Tegal regency. J Matern Child Matern, 2(2), 89-99.

[18] Putrianti, Z. D. (2019). Faktor-Faktor Yang Mempengaruhi Pelaksanaan Inisiasi Menyusu Dini (Imd) Di Klinik Aminah Amin Samarinda. http://repository.poltekkeskaltim.ac.id/id/eprint/219

[19] Cohen, S. S., Alexander, D. D., Krebs, N. F., Young, B. E., Cabana, M. D., Erdmann, P., ... \& Saavedra, J. M. (2018). Factors associated with breastfeeding initiation and continuation: a meta-analysis. The Journal of pediatrics, 203, 190-196. https://doi.org/10.1016/j.jpeds.2018.08.008

[20] Takahashi, K., Ganchimeg, T., Ota, E., Vogel, J. P., Souza, J. P., Laopaiboon, M., ... \& Mori, R. (2017). Prevalence of early initiation of breastfeeding and determinants of delayed initiation of breastfeeding: secondary analysis of the WHO Global Survey. Scientific reports, 7(1), 1-10. https://doi.org/10.1038/srep44868 
[21] Hinson, T. D., Skinner, A. C., Lich, K. H., \& Spatz, D. L. (2018). Factors that influence breastfeeding initiation among African American women. Journal of Obstetric, Gynecologic \& Neonatal Nursing, 47(3), 290-300. https://doi.org/10.1016/j.jogn.2018.02.007

[22] Ningsih, R. R., \& Asthiningsih, N. W. W. (2021). Hubungan Antara Inisiasi Menyusui Dini Dan Budaya Dengan Pemberian ASI Eksklusif Pada Bayi Usia 6-12 Bulan Di Posyandu Wilayah Kerja Puskesmas Harapan Baru Samarinda. Borneo Student Research (BSR), 2(2), 879-886.

[23] Singh, K., Khan, S. M., Carvajal-Aguirre, L., Brodish, P., Amouzou, A., \& Moran, A. (2017). The importance of skin-toskin contact for early initiation of breastfeeding in Nigeria and Bangladesh. Journal of global health, 7(2), 020505. https://doi.org/10.7189/jogh.07.020505

[24] Hassan, N. E., El-Masry, S. A., El Batrawy, S. R., Khalil, A., Ali, M. M., Al Tohamy, M., \& Hashish, M. A. (2018). Relationship between breast feeding duration and risk of overweight/obesity among Egyptian children. Egyptian Pediatric $\begin{array}{lll}\text { Association } \quad \text { Gazette, } & \text { 66(1), }\end{array}$ https://doi.org/10.1016/j.epag.2018.01.001

[25] John, J. R., Mistry, S. K., Kebede, G., Manohar, N., \& Arora, A. (2019). Determinants of early initiation of breastfeeding in Ethiopia: a population-based study using the 2016 demographic and health survey data. BMC pregnancy and childbirth, 19(1), 110. https://doi.org/10.1186/s12884-019-2211-0

[26] Kitano, N., Nomura, K., Kido, M., Murakami, K., Ohkubo, T., Ueno, M., \& Sugimoto, M. (2016). Combined effects of maternal age and parity on successful initiation of exclusive breastfeeding. Preventive medicine reports, 3, 121-126. https://doi.org/10.1016/j.pmedr.2015.12.010.

[27] Juwita, N. E. (2017). Analisis Penghambat Yang Berhubungan Dengan Pelaksanaan Inisiasi Menyusu Dini (Imd) Pada Persalinan Sectio Caesarea Di Rumah Sakit Bersalin Jeumpa Pontianak. Jurnal ProNers, 3(1). DOI: http://dx.doi.org/10.26418/jpn.v3i1.21322 